\title{
The intertwined cultural evolution of ascetic spiritualities and puritanical religions as technologies of self-discipline
}

\author{
Léo Fitouchi ${ }^{1 *}$, Jean-Baptiste André ${ }^{1}$, Nicolas Baumard ${ }^{1}$ \\ ${ }^{1}$ Institut Jean Nicod, Département d'études cognitives, ENS, EHESS, PSL University, CNRS, Paris France
}

To appear in Religion, Brain and Behavior (Book Symposium on Glucklich, A. (2020). The Joy of religion: Exploring the nature of pleasure in spiritual life. Cambridge University Press)

Glucklich's The Joy of religion (2020) makes many fundamental contributions to cognitive and evolutionary approaches to religion. Here, we focus and elaborate on two of them.

The first one pertains to the joyful, hedonic facet of world-religions. While they condemn what Glucklich calls the "novelty-replenishment" pleasures of food, sex, alcohol or gambling, world religions however celebrate another kind of pleasures, derived from the patient self-control of these very short-sighted, animalistic impulses. These "mastery pleasures", as Glucklich calls them, refer to the longer lasting well-being people gain by controlling their dietary and sleep habits, disciplining their body in ascetic rituals, meditation and effortful pilgrimages, or acquiring difficult skills such as reading and memorizing the scriptures.

The second one pertains to the puzzle surrounding the emergence of world religions in the so-called "Axial Age." While most existing cultural evolutionary theories focused on the increasingly moralizing, punitive character of supernatural beliefs exhibited in this period (Baumard \& Chevallier, 2015; Norenzayan et al., 2016; Whitehouse et al., 2019), Glucklich shows that the Axial Age transformation is also an hedonic one. He documents how, in Greece and India in particular, emerged "systematic and conscious reflections" according to which selfcontrol can produce "a distinct sort of pleasure, more elevated, longer lasting and often more intense than the usual sort of pleasures" (pp. 62-63). This points to an important yet often overlooked fact about the emergence of world religions, namely that their moralizing emphasis on the self-control of impulses often develops in tandem with deeply eudaemonic spiritualities, that not only care about virtue, but also about happiness (e.g., Buddhism, Stoicism, Confucianism; Baumard et al., 2015). Crucially, the latter prescribe similarly ascetic and selfdisciplined lifestyles, yet construe them as a path to psychological well-being, whether the latter is two be found in the tranquility of the soul (e.g., Ancient Greek wisdoms), freedom from suffering (e.g., Buddhism, Jainism; Bronkhorst, 2007) or effortless spontaneity in harmony with the universe (Daoism, Confucianism; Slingerland, 2014).

Glucklich's insights and materials should definitely have implications on the way we think about the cultural evolution of world religions. The above remarks, indeed, raise two key cultural evolutionary questions:

1. A question of cultural design: Why do, across "axial" spiritual traditions, a puritanical, moralizing side restricting bodily pleasures, and a joyful side celebrating self-controlderived well-being develop in concert?

2. A question of cultural emergence and diffusion: Why are these two intertwined cultural traits a recent development in human history, characteristic of the economically developed, socially complex societies of the "axial" transition?

"Corresponding author email: leo.fitouchi@ens.fr 
While Glucklich's inquiry into spiritual pleasure is fascinating, the excited reader is somewhat left hungry for systematic answers to these questions. Here, we propose that the cultural affinity between the puritanical and eudaemonic components of axial spiritualities makes sense when one construes them as culturally evolved technologies of self-discipline. By this, we mean a package of psychological theories and techniques that people designed, tweaked and selectively retained because they appeared to them as effective in facilitating the delay of gratification. This increasingly exhibited goal - delaying gratification - had two core facets: facilitating interindividual cooperation one side, which is a long-term strategy, and favoring individual well-being on the long-run, which required resisting the temptations of immediate pleasures.

This dual demand (moral and eudaemonic) for self-control drove the joint cultural evolution of ascetic religions and spiritualities (e.g., Christianity, Buddhism, Jainism, Hinduism, Confucianism, Daoism, Platonism, Pythagoreanism, Stoicism), endowed, with various dosages, with both a puritanical, moralizing tenor (controlling sinful desires for selfish, instant gratification) and a joyful, eudaemonic facet (favoring 'mastery', spiritual pleasures over short-sighted, quickly evaporating ones). Also, this allows to answer the "emergence" question, as the very propensity to favor long-term goals over immediate gratification is known to vary with people's material security, which is known to have dramatically increased in the societies where these spiritualities emerged.

\section{Where does cultural design come from? Cultural evolution as "technological" accumulation for satisfying human goals}

Cultural evolution refers to population-level changes in the distribution of socially transmitted traits, through which certain variants end up (i) being more widespread than other in a population of individuals, and (ii) having design-like features (Henrich, 2017; Nettle, 2020; Richerson \& Boyd, 2005). Influent approaches often insist on selective processes, by which inheritable variations in cultural reproductive success lead the "fittest" cultural variants to invade a population, ending up producing "cultural adaptations" (Henrich, 2017; Richerson \& Boyd, 2005). Importantly, it is often proposed that such a cultural selection produces functional tools, beliefs and practices independently of people's understanding of the mechanisms they involve or the function they serve (Derex et al., 2019; Henrich, 2017).

This approach has often been applied to moralizing religions, proposed to have culturally evolved because of the group-level selection pressures exerted on societies by intergroup competition, favoring beliefs and cultural systems well suited for large-scale cooperation (Norenzayan et al., 2016). Regarding the aforementioned "design" question, Glucklich (2020) similarly suggests that "the curtailment of novelty pleasures and promotion of mastery pleasure ... was useful for the survival and prospering of groups in evolutionary and historical times" (p. 144).

Another possibility, however, is that cultural design emerges not because of "blind" selective forces operating independently of individuals' motivations and understanding, but rather develops from their evaluations of how well some cultural variants satisfy their goals (Singh, 2020). For example, there is ample evidence that the cultural evolution of technologies is largely driven by people's technical reasoning skills, allowing them to design, tweak and selectively retain over generations the most effective-seeming variants of tools (Osiurak \& Reynaud, 2019). Crucially, such processes are likely to drive the evolution not only of technological culture in the strict sense, but also of "symbolic" and normative domains of human culture (André et al., 2020; Singh, 2020). This seems to be the case for narratives designed to pleasurably trigger human social cognition (Nettle, 2005; Singh, 2019; Dubourg 
\& Baumard, 2020), norms designed for the self-interest of rulers (Betzig, 1986; Singh et al., 2017) or the mutual benefit of individuals involved (Alvard \& Nolin, 2002; Ostrom, 1990), shamanistic practices convincing clients of the practitioner's ability to interact with supernatural agents (Singh, 2018) or divination procedures aimed at forging consensus on undecidable questions (Boyer, 2020).

All this suggests that we should perhaps look at culture in general in the way we think about technological evolution: people intentionally design, convergently transform (Claidière et al., 2018), and selectively retain, based on the intuitions and information available to them, cultural variants appearing to them as increasingly satisfying their goals (Singh, 2020). We suggest that ascetic spiritualities found in world religions should likewise be considered as a particular type of culturally evolved "technology" (or "cultural capital"; André \& Baumard, 2020), which have the interesting specificity of having as its object, not tools or weapons, but the buman psychology itself. These cultural traditions, we propose, developed as individuals exploited their folk understanding of the human hedonic psychology, to design and retain techniques aimed at nudging it, hacking it, and even rewiring it, in order to more easily delay gratification in the pursuit of two increasingly valued long-term outcomes: cooperation and psychological well-being.

\section{Technologies of self-discipline for "the good life": Goals, theories and techniques in ancient wisdoms}

Ascetic practices are not restricted to "axial" religions and large-scale societies. In small-scale societies, initiation rituals often impart harsh restrictions on bodily desires (e.g., Gusinde, 1931; Kan, 1989) and shamans are often subjected to restrictions on food or sex (Singh, 2018), potentially consisting in hard-to-fake signals of cooperative commitment (Sosis, 2006; Sosis \& Alcorta, 2003) or credible displays of the supernatural powers they claim (Singh \& Henrich, 2020). What seems new, however, is the distinctive psychological goal asceticism seems to serve in the Axial Age, namely cultivating the self-control required for cooperative behavior and long-term happiness - "the good life", as the Greeks said. This is suggested the design of the theories and techniques they develop.

\section{Psychological theories of two delay of gratification problems}

As emanating from Glucklich's book, these traditions developed explicit theories about the human psychology. These theories commonly emphasize the conflict between bodily pleasures on one side, and long-term well-being and cooperative behavior on the other.

A commonplace of axial doctrines is indeed that long-term satisfaction is poorly sustained by "novelty-replenishment" pleasures. This can be because of the fugitive, quickly evaporating gratification they offer. Or because they are associated with intense cravings impeding a clear vision of the world and wise decision-making. Or because of the psychological suffering tied to these craving when they are not satisfied. Or because they generate incessantly renewed desires for a new stimulation, leaving individuals in an endless cycle of perpetual dissatisfaction. Or because excessive indulgence in bodily pleasures and material comfort makes one's well-being dependent on external conditions that could well disappear in the future. This is found, with various dosages and obviously different metaphysical backgrounds, in Stoicism, Epicureanism, Platonism, Pythagoreanism, Christianity (Finn, 2009; Gaca, 2003; Irvine, 2009), Buddhism, Jainism, Hinduism (Bronkhorst, 2007; Thurman, 2002; Wright, 2017) and to some extent Daoism and Confucianism (Csikszentmihalyi, 2004; Luo, 2019). 
In other words, axial spiritualities seem underpinned by a common, often religiously or philosophically explicated intuition of a delay of gratification problem: the immediate rewards provided by bodily and materialistic pleasures are not worth their long-term costs.

A second common theme of Axial doctrines concerns what ultimately represents another temporal discounting problem, namely the conflict between immediate gratification and cooperation. At the ultimate level, cooperation is indeed a long-term strategy, by which individuals have to forgo the immediate selfish rewards brought by free-riding, and wait for the delayed benefits of future reciprocations and a good reputation (Fitouchi et al., 2020; Stevens et al., 2005; Trivers, 1971). Accordingly, at the psychological level, behaving cooperatively often requires the self-control of impulses for immediate pleasures (e.g, food, sexual opportunity, rest) (Hofmann et al., 2018), and self-control predicts cooperative behavior in various domains of social life (Cohen et al., 2014; Fehr \& Leibbrandt, 2011; Vazsonyi et al., 2017).

Again, a theorizing of this psychological conflict is central to axial doctrines, which depict the appetites for food, sex or drink as sinful urges threatening moral righteousness, and self-control, discipline and temperance as core moral virtues. For example, Glucklich does an admirable job identifying particularly early manifestations of this cultural change in the Hindu Ramayana and the Greek Iliad (p. 77-83). More generally, the intuition that taming impulses for immediate gratification is a prerequisite for cooperative behavior recurrently underlies puritanical condemnations of bodily pleasures across moralizing religions (Glucklich, 2020; Fitouchi et al., 2020).

\section{Culturally evolved self-control techniques}

Consistent with this dual demand (moral and eudaemonic) for self-control, axial asceticism is typically characterized by what psychologists now call "strategies of self-control" (Duckworth, Gendler, et al., 2016; McCullough \& Carter, 2013) aimed at more easily resisting temptations. Several observations suggest that these evolved through goal-directed "technological" accumulation for facilitating the delay of gratification, rather than blind (group-level) selective forces. First, in contemporary populations, people (even children) often spontaneously develop similar, albeit less sophisticated techniques to facilitate the delay of gratification (Duckworth, White, et al., 2016; Mischel \& Mischel, 1983; Peake et al., 2002). Second, these techniques are finely tuned to the psychological goals and theories described above.

For example, the use of meditation and mental self-observation, found across ascetic spiritualities, is often meant to undercut temptation at its root, by cautiously monitoring impulses' appearances in consciousness, or merely observing them in a "detached" manner, without succumbing to their motivational power (e.g., Buddhism: Wright, 2017; Christianity: Spiegel, 2020; later in history, Neo-Confucianism: Tiwald, 2020; Calvinism: Gorski, 2003).

Some techniques are more akin to "preventive" strategies of self-control (Duckworth, Gendler, et al., 2016; Hofmann \& Kotabe, 2012), by which individuals rearrange their environment upstream to limit impulses' influence on actual behavior. For example, many scholars of early China highlighted that the rigorous ritual discipline required by Confucianism (e.g., strict rules of etiquette), was meant to restrict individuals' behavioral possibilities upstream, functioning "as a kind of block against or prevention of the influence of desires or selfish behavior” (Csikszentmihalyi, 2009, p. 253).

Ascetic and disciplined lifestyles in general were construed as a long-term, patient training aiming at more profoundly "rewiring" the individual psychology, by regularly practicing self-control, moderation and restraint (Thurman, 2002; Irvine, 2009; Gaca, 2003, 
later in history: Gorski, 2003). Again, depending on the traditions, this long-term hedonic rewiring was either meant to achieve happiness (e.g., "liberation" and "enlightenment" in Buddhism; Thurman, 2002) or moral righteousness (e.g., "train[ing] the soul to decline genuinely appealing immoral choices" in Christianity, Spiegel, 2020, p. 20). Relatedly, Chinese traditions developed (similarly to Aristotelian virtue ethics) what today would be called "habit formation" techniques (Carden \& Wood, 2018), aimed at making behaviors that initially require effortful self-control become spontaneous and automatic (Slingerland, 2014). This seems particularly important in Confucianism, in which the strict observance of rituals and etiquette consists in a "behavioral training", aimed at "carving and reshaping the self", in order to "replac[e] innate, problematic dispositions with new, socially desirable ones", so that "there is no more need for cognitive control" for cooperative behavior to be enacted (Slingerland, 2014, pp. 77, 80).

\section{Back to the design question}

Although a systematic assessment would obviously be required, the doctrines and techniques characteristic of puritanical religions and ascetic spiritualities suggest that they evolved as technologies of self-discipline for satisfying two long-term goals - facilitating cooperation and individual well-being. These goals, although distinct, indeed share a common conflict with short-term impulses for immediate gratification (Hofmann et al., 2014, 2018). And from this common conflict seems to result, at the cultural level, a frequent co-occurrence of puritanical religions exhibiting a moralizing asceticism (condemnations of bodily pleasures) and more 'joyful' ascetic spiritualities, where self-control plays a more eudaemonic function (see Table 1). Figure 1 illustrates this cultural affinity between three cultural traits (puritanical morality, ascetic spiritualities, prosocial religions) resulting from the psychological relationships existing between self-control, cooperation and long-term well-being. 


\begin{tabular}{|c|c|c|}
\hline & Puritanical religions & Ascetic spiritualities \\
\hline Psychological goal & Enforcing cooperation & Favoring happiness \\
\hline Culturally evolved means & \multicolumn{2}{|c|}{$\begin{array}{l}\text { Technologies of self-discipline: } \\
\text { - Training self-control ; formation of long-term oriented habits } \\
\text { (e.g., sexual restraint, moderation in food, voluntary poverty, } \\
\text { sober lifestyle, fasting, effortful activities) } \\
\text { - Preventive strategies of self-control (e.g., abstention from } \\
\text { alcohol, strict ritual observance) } \\
\text { - Intra-psychic strategies of self-control (e.g., meditation, self- } \\
\text { observation, moral diaries) }\end{array}$} \\
\hline Core cultural manifestations & $\begin{array}{l}\text { 'Moralizing asceticism': } \\
\text { - Techniques of self-control } \\
\text { are moral obligations (e.g., } \\
\text { ethic of self-discipline, } \\
\text { religious prescription of } \\
\text { fasting, prohibition of } \\
\text { alcohol) } \\
\text { - Immediate pleasures are } \\
\text { morally condemned (e.g., } \\
\text { 'Seven deadly sins). }\end{array}$ & $\begin{array}{l}\text { 'Eudaemonic asceticism': } \\
\text { - Techniques of self-control are } \\
\text { valued because of the pleasant } \\
\text { psychological states they } \\
\text { bring ("mastery pleasures", } \\
\text { e.g., meditation) }\end{array}$ \\
\hline
\end{tabular}

Table 1. Commonalities and differences between puritanical religions and ascetic wisdoms, and their respective relations to self-discipline, the enforcement of cooperation and the quest for happiness. 


\section{Prosocial religions}

Defining feature: Morally textured supernatural beliefs, such as cosmic justice (the world is overall fair), supernatural agents enforcing human morality, heaven \& hell, etc.

(Medieval

Christianity)

Islam

(Orthodox)

Haredi Judaism

Protestant ethic of self-discipline

Secular moral conservatism

\section{Early Christianity ('Desert fathers')}

\section{Islam \\ (Sufism) \\ Chan Buddhism \\ Daoism}

Simple living in Christianity (e.g. Francis of Assisi)

\section{Greek \\ Stoicism \\ Epicureanism, Cynicism}

\section{Confucianism Buddhism}

\section{Contemporary}

'self-help', 'New Age' and 'personal development'

Defining feature: enforcing cooperation through:

- prescription of self-discipline as a facilitator of cooperative behavior

- condemnation of short-term bodily pleasures as facilitators of free-riding

\section{Puritanical morality \\ Ascetic spiritualities}

Roman Stoicism,

Platonism,

Pythagoreanism
Defining feature: favoring individual long-term wellbeing and achievements, through moderation, selfdisciplined lifestyles and enjoyment of 'mastery pleasures'

Figure 1. The "Axial" constellation. The diagram describes the overlapping types of religious, spiritual and moral traditions typical of the "Axial Age" transition. "Axial" here is not used as a historical term referring to the second half of the first millennium B.C., but as capturing a typical cultural from that many spiritual traditions exhibit since then (insisting on morality and self-discipline), as opposed to the supernatural beliefs and practices of small-scale and archaic societies (Boyer \& Baumard, 2016). Puritanical moralities refer to the enforcement of cooperation through the moralization of bodily pleasures, and the symmetric moral praise of self-control. Ascetic spiritualities share with puritanical morality a valorization of self-control and moderation in bodily pleasures, which however targets their relation to happiness rather than to cooperation. Prosocial religions share with puritanical morality a concern for the enforcement of cooperation, which manifests itself in supernatural beliefs. The placement of the few examples on the diagram is of course highly approximative - many alternate arrangements could be justified -, and does not reflect the internal variety and complexity of each tradition (e.g., there is no such thing as "Buddhism" in general). It is only illustrative of the general affinity between three cultural traits (puritanical morality, ascetic spirituality, prosocial religion) finding themselves combined with various dosages in different cultural traditions. 


\section{Increased affluence, moralizing religions and the "discovery of mastery pleasure"}

This leaves us with the question of cultural emergence: why do these long-term goals, and the associated techniques, develop so late in human history? Glucklich suggests, at times, that the emergence of "mastery pleasure" was made possible by abstract intellectual changes: a transition from "mythic" to "theoretic culture" (Bellah, 2011; Donald, 1993), allowing new conceptualizations of pleasure. An alternate, compatible possibility is that the change occurred in people's motivations and reward systems (Baumard, Hyafil, \& Boyer, 2015). At the psychological level, pleasures are indeed by definition a matter of rewards. At the cultural level, changing psychological goals are also likely to drive the evolution of new cultural forms designed to satisfy those goals.

In this regard, the centrality of self-control in axial spiritualities cannot but make us think of the fact that people's propensity to favor long-term goals over immediate gratification substantially varies as a function of their material security. At the ultimate level, in deprived environments characterized by a high collection risk, i.e. where the probability to get a reward at the end of a delay is low because of the future's uncertainty, it is more advantageous to prefer immediate rewards to delayed ones that are less guaranteed (Pepper \& Nettle, 2017; Baumard, 2019 , for reviews). Recent modelling work also showed that the greater waiting costs associated to a low initial endowment in economic and embodied capital can favor steeper timediscounting in deprived environments, as people cannot afford to forgo immediate opportunities to satisfy basic, pressing needs (e.g., alimentary security) having a high return on investment (Mell et al., 2019). Accordingly, within societies, people living in affluence, compared to people of lower socio-economic status, orient more toward distant goals (Haushofer \& Fehr, 2014; Pepper \& Nettle, 2017). Relatedly, exogenous shocks in resource transfers to households seem to cause relatively large increases in childrens' conscientiousness, a construct related to trait self-control (Akee et al., 2018). Across societies, differences in longterm orientation are also robustly associated to GDP per capita, after controlling for many potential confounds (Dohmen et al., 2018).

As a result, favoring asceticism and self-control in the quest for long-term, "higher" pleasures and cooperativeness probably makes sense only when one's alimentary and material security is already ensured. Moreover, psychological research suggests that people scoring higher in trait self-control are precisely the ones who the more readily develop self-control techniques (Ent et al., 2015) and form long-term oriented habits (Adriaanse et al., 2014; Gillebaart \& Adriaanse, 2017), as axial spiritualities prescribe.

We should thus expect that the more affluent the environment, the more cultural traditions developing various techniques for facilitating self-discipline should culturally evolve. Accordingly, places where ascetic wisdoms and moralizing religions emerged (in the Mediterranean, India and China) reached unprecedented levels of affluence in the first millennium B.C. (Baumard, Hyafil, Morris, et al., 2015). Baumard, Huillery \& Zabrocki (2018) also studied changes in the extent to which asceticism was valued during the European Middle Ages (600-1600), when economic development increased again in Europe. Using biographies of the Saints canonized during this period, they investigated changes in the valorization of renunciation to bodily pleasures and material possessions in the process of canonization. To assess the causal impact of economic growth on the valorization of asceticism, they used the introduction of the heavy plow as an instrumental variable for economic prosperity (following Andersen et al., 2016) and showed that economic growth, measured by population density, was associated with an increased valorization of asceticism - even after 
controlling for various potential confounds such as the number of books, universities or monasteries per capita.

\section{Conclusion}

Altogether, this suggests that the association, finely described and psychologically characterized by Glucklich, between moralizations of 'novelty replenishment' pleasures and celebrations of 'mastery pleasures', might be explained by closely investigating the cultural evolutionary foundations of ascetic religions and spiritualities. To this aim, research integrating the expertise of historians and social scientists of religion with cognitive-evolutionary approaches are particularly valuable. In this regard, this interdisciplinary field definitely needs more works such as The Joy of Religion.

\section{References}

Adriaanse, M. A., Kroese, F. M., Gillebaart, M., \& De Ridder, D. T. D. (2014). Effortless inhibition: Habit mediates the relation between self-control and unhealthy snack consumption. Frontiers in Psychology, 5. https://doi.org/10.3389/fpsyg.2014.00444

Akee, R., Simeonova, E., Costello, E. J., \& Copeland, W. (2018). How Does Household Income Affect Child Personality Traits and Behaviors?, American Economic Review, 108(3), 775-827.

Alvard, M. S., \& Nolin, D. A. (2002). Rousseau's Whale Hunt?: Coordination among Big-Game Hunters. Current Anthropology, 43(4), 533-559. https://doi.org/10.1086/341653

Andersen, T. B., Jensen, P. S., \& Skovsgaard, C. V. (2016). The heavy plow and the agricultural revolution in Medieval Europe. Journal of Development Economics, 118, 133-149. https://doi.org/10.1016/j.jdeveco.2015.08.006

André, J.-B., \& Baumard, N. (2020). Cultural evolution by capital accumulation. Evolutionary Human Sciences, 2, e18. https://doi.org/10.1017/ehs.2020.19

André, J.-B., Baumard, N., \& Boyer, P. (2020). The Mystery of Symbolic Culture: What fitness costs? What fitness benefits? [Preprint]. Open Science Framework. https://doi.org/10.31219/osf.io/kdh7t

Baumard, N. (2019). Psychological origins of the Industrial Revolution. Behavioral and Brain Sciences, 42, e189. h ttps://doi.org/10.1017/S0140525X1800211X

Baumard, N., \& Chevallier, C. (2015). The nature and dynamics of world religions: A life-history approach. Proceedings of the Royal Society B: Biological Sciences, 282(1818), 20151593. https://doi.org/10.1098/rspb.2015.1593

Baumard, N., Huillery, E., \& Zabrocki, L. (2018). The Origins of Romantic Love and Asceticism: How Economic Prosperity Changed Human Psychology in Medieval Europe. Working paper, 42.

Baumard, N., Hyafil, A., \& Boyer, P. (2015). What changed during the axial age: Cognitive styles or reward systems? Communicative E' Integrative Biology, 8(5), e1046657. https://doi.org/10.1080/19420889.2015.1046657

Baumard, N., Hyafil, A., Morris, I., \& Boyer, P. (2015). Increased Affluence Explains the Emergence of Ascetic Wisdoms and Moralizing Religions. Current Biology, 25(1), 10-15. https://doi.org/10.1016/j.cub.2014.10.063

Bellah, R. N. (2011). Religion in Human Evolution. Harvard University Press.

Betzig, L. L. (1986). Despotism and differential reproduction: A Darwinian view of history (pp. xi, 171). Aldine Publishing Co.

Boyer, P. (2020). Why Divination?: Evolved Psychology and Strategic Interaction in the Production of Truth. Current Anthropology, 000-000. https://doi.org/10.1086/706879

Boyer, P., \& Baumard, N. (2016). The Diversity of Religious Systems Across History. In The Oxford Handbook of Evolutionary Psychology and Religion. (Vol. 1, pp. 1-25). Oxford University Press. https://doi.org/10.1093/oxfordhb/9780199397747.001.0001

Bronkhorst, J. (2007). Greater Magadha: Studies in the culture of early India. Brill.

Carden, L., \& Wood, W. (2018). Habit formation and change. Current Opinion in Behavioral Sciences, 20, 117-122. https://doi.org/10.1016/j.cobeha.2017.12.009

Claidière, N., Amedon, G. K., André, J.-B., Kirby, S., Smith, K., Sperber, D., \& Fagot, J. (2018). Convergent transformation and selection in cultural evolution. Evolution and Human Behavior, 39(2), 191-202. https://doi.org/10.1016/j.evolhumbehav.2017.12.007

Cohen, T. R., Turan, N., Panter, A. T., Morse, L., \& Kim, Y. (2014). Moral Character in the Workplace, Journal of Personality and Social Psychology, 107(5), 943-963.

Csikszentmihalyi, M. (2004). Material virtue: Ethics and the body in early China. Brill.

Csikszentmihalyi, M. (2009). Ethics And Self-Cultivation Practice In Early China. Early Chinese Religion, Part One: Shang through Han (1250 BC-220 AD) (2 Vols.), 519-542.

Derex, M., Bonnefon, J.-F., Boyd, R., \& Mesoudi, A. (2019). Causal understanding is not necessary for the improvement of culturally evolving technology. Nature Human Behaviour, 3(5), 446-452. https://doi.org/10.1038/s41562-019- 
0567-9

Dohmen, T., Enke, B., Falk, A., Huffman, D., \& Sunde, U. (2018). Patience and Comparative Development. Working paper.

Donald, M. (1993). Origins of the Modern Mind: Three Stages in the Evolution of Culture and Cognition. Harvard University Press.

Dubourg, E. \& Baumard, N. (2020) Why Imaginary Worlds? The psychological foundations and cultural evolution of world-dominant fictions, Working paper.

Duckworth, A. L., Gendler, T. S., \& Gross, J. J. (2016). Situational Strategies for Self-Control. Perspectives on Psychological Science, 11(1), 35-55. https://doi.org/10.1177/1745691615623247

Duckworth, A. L., White, R. E., Matteucci, A. J., Shearer, A., \& Gross, J. J. (2016). A stitch in time: Strategic self-control in high school and college students. Journal of Educational Psychology, 108(3), 329-341. https://doi.org/10.1037/edu0000062

Ent, M. R., Baumeister, R. F., \& Tice, D. M. (2015). Trait self-control and the avoidance of temptation. Personality and Individual Differences, 74, 12-15. https://doi.org/10.1016/j.paid.2014.09.031

Fehr, E., \& Leibbrandt, A. (2011). A field study on cooperativeness and impatience in the Tragedy of the Commons. Journal of Public Economics, 95(9-10), 1144-1155. https://doi.org/10.1016/j.jpubeco.2011.05.013

Finn, R. (2009). Asceticism In The Graeco-Roman World. Cambridge University Press.

Fitouchi, André \& Baumard (2020). Moral disciplining: the cognitive and evolutionary foundations of puritanical morality. Working paper.

Gaca, K. L. (2003). The Making of Fornication: Eros, Ethics, and Political Reform in Greek Philosophy and Early Christianity. University of California Press.

Gillebaart, M., \& Adriaanse, M. A. (2017). Self-control Predicts Exercise Behavior by Force of Habit, a Conceptual Replication of Adriaanse et al. (2014). Frontiers in Psychology, 8. https://doi.org/10.3389/fpsyg.2017.00190

Glucklich, A. (2020). The joy of religion: exploring the nature of pleasure in spiritual life. Cambridge University Press.

Gorski, P. S. (2003). The disciplinary revolution: Calvinism and the rise of the state in early modern Europe. University of Chicago Press.

Gusinde, M. (1931). The Fireland Indians: Vol. 1. The Selk'Nam, On The Life And Thought Of A Hunting People Of The Great Island Of Tierra Del Fuego. Verlag der Internationalen Zeitschrift. https://ehrafworldcultures-yaleedu.proxy.library.upenn.edu/document?id=sh04-001

Haushofer, J., \& Fehr, E. (2014). On the psychology of poverty. Science, 344(6186), 862-867. https://doi.org/10.1126/science.1232491

Henrich, J. (2017). The Secret of Our Success: How Culture Is Driving Human Evolution, Domesticating Our Species, and Making Us Smarter. Princeton University Press.

Hofmann, W., \& Kotabe, H. (2012). A General Model of Preventive and Interventive Self-Control: PI-Model of SelfControl. Social and Personality Psychology Compass, 6(10), 707-722. https://doi.org/10.1111/j.17519004.2012.00461.x

Hofmann, W., Luhmann, M., Fisher, R. R., Vohs, K. D., \& Baumeister, R. F. (2014). Yes, But Are They Happy? Effects of Trait Self-Control on Affective Well-Being and Life Satisfaction: Trait Self-Control and Well-Being. Journal of Personality, 82(4), 265-277. https://doi.org/10.1111/jopy.12050

Hofmann, W., Meindl, P., Mooijman, M., \& Graham, J. (2018). Morality and Self-Control: How They Are Intertwined and Where They Differ. Current Directions in Psychological Science, 27(4), 286-291.

Irvine, W. B. (2009). A guide to the good life: The ancient art of Stoic joy. Oxford University Press.

Kan, S. (1989). Symbolic Immortality: The Tlingit Potlatch Of The Nineteenth Century. Smithsonian Institution Press. https://ehrafworldcultures-yale-edu.proxy.library.upenn.edu/document?id=na12-032

Luo, S. (2019). Happiness and the Good Life: A Classical Confucian Perspective. Dao, 18(1), 41-58. https://doi.org/10.1007/s11712-018-9640-8

McCullough, M. E., \& Carter, E. C. (2013). Religion, self-control, and self-regulation: How and why are they related? In APA handbook of psychology, religion, and spirituality (Vol 1): Context, theory, and research (pp. 123-138). American Psychological Association. https://doi.org/10.1037/14045-006

Mell, H., Baumard, N., \& André, J.-B. (2019). Time is money. Waiting costs explain why selection favors steeper time discounting in deprived environments. [Preprint]. EcoEvoRxiv. https://doi.org/10.32942/osf.io/7d56s

Mischel, H. N., \& Mischel, W. (1987). The Development of Children's Knowledge of Self-Control Strategies. In Motivation, intention, and volition (pp. 321-336). Springer, Berlin, Heidelberg. 603-619

Nettle, D. (2005). The Wheel of Fire and the Mating Game: Explaining the Origins of Tragedy and Comedy, Journal of Cultural and Evolutionary Psychology, 3(1), 39-56.

Nettle, D. (2020). Selection, adaptation, inheritance and design in human culture: The view from the Price equation. Philosophical Transactions of the Royal Society B: Biological Sciences, 375(1797), 20190358. https://doi.org/10.1098/rstb.2019.0358

Norenzayan, A., Shariff, A. F., Gervais, W. M., Willard, A. K., McNamara, R. A., Slingerland, E., \& Henrich, J. (2016). The cultural evolution of prosocial religions. Behavioral and Brain Sciences, 39. https://doi.org/10.1017/S0140525X14001356

Osiurak, F., \& Reynaud, E. (2019). The Elephant in the Room: What Matters Cognitively in Cumulative Technological Culture. Behavioral and Brain Sciences, 1-57. https://doi.org/10.1017/S0140525X19003236 
Ostrom, E. (1990). Governing the Commons: The Evolution of Institutions for Collective Action. Cambridge University Press.

Peake, P. K., Hebl, M., \& Mischel, W. (2002). Strategic attention deployment for delay of gratification in working and waiting situations. Developmental Psychology, 38(2), 313-326. https://doi.org/10.1037/0012-1649.38.2.313

Pepper, G. V., \& Nettle, D. (2017). The behavioural constellation of deprivation: Causes and consequences. Behavioral and Brain Sciences, 40. https://doi.org/10.1017/S0140525X1600234X

Richerson, P. J., \& Boyd, R. (2005). Not by genes alone: How culture transformed human evolution. University of Chicago Press.

Singh, M. (2018). The cultural evolution of shamanism. Behavioral and Brain Sciences, 41. https://doi.org/10.1017/S0140525X17001893

Singh, M. (2019). The sympathetic plot: Identifying and explaining a narrative universal. PsyArXiv. https://doi.org/10.31219/osf.io/p8q7a

Singh, M. (2020). Subjective selection and the evolution of complex culture. PsyArXiv. https://doi.org/10.31234/osf.io/4t2ud

Singh, M., \& Henrich, J. (2020). Why do religious leaders observe costly prohibitions? Examining taboos on Mentawai shamans. Evolutionary Human Sciences, 2, e32. https://doi.org/10.1017/ehs.2020.32

Singh, M., Wrangham, R., \& Glowacki, L. (2017). Self-Interest and the Design of Rules. Human Nature, 28(4), 457-480. https://doi.org/10.1007/s12110-017-9298-7

Slingerland, E. G. (2014). Trying not to try: The art and science of spontaneity (First Edition). Crown Publishers.

Sosis, R. (2006). Religious behaviors, badges, and bans: Signally theory and the evolution of religion. In P. McNamara (Ed.) Where God and Science Meet, 61-86.

Sosis, R., \& Alcorta, C. (2003). Signaling, solidarity, and the sacred: The evolution of religious behavior. Evolutionary Anthropology: Issues, News, and Reviews, 12(6), 264-274. https://doi.org/10.1002/evan.10120

Spiegel, J. S. (2020). Cultivating Self-Control: Foundations and Methods in the Christian Theological Tradition. Journal of Spiritual Formation and Soul Care, 1939790920918881.

Stevens, J. R., Cushman, F. A., \& Hauser, M. D. (2005). Evolving the Psychological Mechanisms for Cooperation. Annual Review of Ecology, Evolution, and Systematics, 36(1), 499-518. https://doi.org/10.1146/annurev.ecolsys.36.113004.083814

Thurman, R. (2002). Tibetan Buddhist Perspectives on Asceticism. In Wimbush, V. L., \& Valantasis, R. (Eds.). Asceticism. Oxford University Press.

Tiwald, J. (2020). Song-Ming Confucianism. In E. N. Zalta (Ed.), The Stanford Encyclopedia of Philosophy (Summer 2020). Metaphysics Research Lab, Stanford University. https://plato.stanford.edu/archives/sum2020/entries/song-mingconfucianism/

Trivers, R. (1971). The Evolution of Reciprocal Altruism. Quarterly Review of Biology 46(1), 35-57.

Vazsonyi, A. T., Mikuška, J., \& Kelley, E. L. (2017). It's time: A meta-analysis on the self-control-deviance link. Journal of Criminal Justice, 48, 48-63. https://doi.org/10.1016/j.jcrimjus.2016.10.001

Whitehouse, H., François, P., Savage, P. E., Currie, T. E., Feeney, K. C., Cioni, E., Purcell, R., Ross, R. M., Larson, J., Baines, J., ter Haar, B., Covey, A., \& Turchin, P. (2019). Complex societies precede moralizing gods throughout world history. Nature, 568(7751), 226-229. https://doi.org/10.1038/s41586-019-1043-4

Wright, R. (2017). Why Buddhism is true: The science and philosophy of meditation and enlightenment. Simon and Schuster. 